\section{Measuring and improving the quality of NHS care for children and young people}

\author{
Dougal S Hargreaves, ${ }^{\oplus 1,2}$ Claire Lemer, $^{3,4}$ Carol Ewing, ${ }^{5,6}$ \\ Jacqueline Cornish, ${ }_{1}^{4}$ Ted Baker, ${ }_{1}^{7}$ Keiko Toma, ${ }_{1}^{7}$ Sonia Saxena, ${ }_{1}^{8}$ \\ Bernadette McCulloch, ${ }^{9}$ Lesley McFarlane, ${ }^{9}$ Jack Welch, ${ }^{10}$ \\ Emma Sparrow, ${ }^{6}$ Lucia Kossarova, ${ }^{2}$ Daniel Edward Lumsden, ${ }^{11}$ \\ C Ronny L H Cheung ${ }^{3}$
}

\section{BACKGROUND}

Children and young people (CYP) in the UK suffer worse health and well-being outcomes than their peers in comparable countries across a range of physical and mental health measures, including overall mortality and deaths from long-term conditions such as epilepsy, asthma and diabetes. ${ }^{1-6}$ While social determinants, in particular relatively high rates of child poverty, account for some of this mortality gap, there is growing evidence that many deaths could be prevented through more accessible and higher quality National Health Service (NHS) care. ${ }^{23}$

In addition, evidence suggests that the NHS care typically results in worse patient experience for young people aged 16-24 than older adults, ${ }^{7}$ and that there is sometimes objectively lower quality care for CYP than for adults. The UK ranked fourth out of 30 countries in a recent comparison of the quality of adult diabetes care, whereas the quality and outcomes of diabetes for patients aged 0-24 years lag well behind that of comparable countries. ${ }^{8} 9$ In addition to moral, public health and economic arguments for improving care quality for CYP, the UK also has legal obligations under the United Nations Convention on the Rights

\footnotetext{
'Population, Policy and Practice Programme, UCL Institute of Child Health, London, UK ${ }^{2}$ Nuffield Trust, London, UK

${ }^{3}$ General Paediatrics, Evelina London Children's Hospital, London, UK

${ }^{4} \mathrm{NHS}$ England, London, UK

${ }^{5}$ Department of Paediatrics, Royal Manchester Children's Hospital, Manchester, UK

${ }^{6}$ Royal College of Paediatrics and Child Health, London, UK

${ }^{7}$ Care Quality Commission, London, UK ${ }^{8}$ Imperial College London, London, UK

${ }^{9} \mathrm{NHS}$ Healthcare Improvement Scotland, Glasgow, UK ${ }^{10}$ RCPCH \& Us Children, Young People and Families Network, London, UK

${ }^{11}$ Complex Motor Disorder Service, Evelina London Children's Hospital, London, UK
}

Correspondence to Dr Dougal S Hargreaves, Population, Policy \& Practice Programme, UCL Institute of Child Health, London WC1N 1EH, UK; d.hargreaves@ucl.ac.uk of the Child to provide the best healthcare possible (article 24) and to involve CYP in decisions that affect them (article 12). ${ }^{10-12}$

Validated and appropriate quality measures are necessary (but not sufficient) to improve care quality and health and well-being outcomes. ${ }^{13}$ CYP have historically been under-represented in many quality frameworks; for example, one 2015 study reported that 0/77 indicators in the Quality Outcomes Framework for primary care were applicable to $\mathrm{CYP}^{14}$ Following the recommendations of the CYP Health Outcomes Forum, ${ }^{15}$ the number of indicators in the NHS Outcomes Framework has increased, ${ }^{16}$ and the perspectives of CYP using NHS services have been given greater weight in some settings. ${ }^{17}$ However, there has been limited response to many of the Forum's recommendations, and many of the indicators that have been introduced are of limited benefit, as they have not been validated for this age group and/or CYP data are aggregated with those of older adults.

Building on previous recommendations by the Chief Medical Officer for England ${ }^{1}$ and the CYP Health Outcomes Forum, ${ }^{15}$ and as a follow-up to the publication of the Royal College of Paediatrics and Child Health (RCPCH) services standards, ${ }^{18} 19$ the $\mathrm{RCPCH}$ initiated a 2 -year project to agree on 5-10 core quality measures for acute general paediatric care. The final 2016 report $^{20}$ represents an important advance in bringing together key principles for measuring and improving quality in acute general paediatric services (see box 1), but the project was not able to reach agreement on its original goal. One key barrier was the lack of a common language and framework for understanding the purpose of measuring quality, what should be measured and how; we attempt to address these concerns in the sections below and in box 1 . Another recurring issue was the lack of knowledge about existing quality measures and data sources. This was addressed by convening a workshop in May 2017 to which each relevant national body was invited to submit their existing measures, as well as related challenges and priorities for future work. A summary of this material is presented in table 1 . Lastly, a relative lack of primary research was noted in developing, validating and implementing appropriate quality measures. ${ }^{21}$

\section{KEY CONCEPTS IN QUALITY AND MEASUREMENT}

Analysis of existing indicators and subsequent workshop discussions revealed a lack of clarity around the key questions relating to quality measurement: 'Why measure?' 'What to measure?' and 'How to measure'. Box 1 summarises important concepts relating to these questions. The tensions and interactions between these factors can be complex and are often not fully appreciated. ${ }^{13}$

First, distinct indicators may be needed for different purposes-no single quality measure or set of measures is likely to be appropriate for the purposes of quality improvement (QI), quality assurance, research, and supporting informed choice. For example, measures that are appropriate for QI (where the focus is often on improving one or more aspects of care quality at the local level) may be less helpful if used for quality assurance (where the aim is to reduce variation and hold providers accountable for care quality, and may therefore require significantly greater rigour in data quality and attribution to individual services). However, services which engage in quality improvement and research typically have better leadership teams, safety records and clinical outcomes than other services, suggesting these activities may in themselves provide an added degree of assurance about care quality. $^{22} 23$

Second, while the National Quality Board (NQB) framework emphasises the importance of a shared view of quality across patients and families, professionals, providers, commissioners and funders, and national bodies, there has been little work to understand the different perspectives between different groups. For example, the optimal balance between short-term pain or inconvenience and expected longterm benefit will often be viewed differently by children, their parents/carers and their doctors. Further, there is likely to be a wide range of views among CYP and their parents/carers on these issues; defining high-quality care may involve trade-offs between supporting patient/family choice and ensuring the best possible health and 
Box 1 Why, what and how to

measure quality

Why measure?*

- Quality improvement.

- Accountability and performance management (often called quality assurance).

- To support informed choices by patients and families.

- Research.

What to measure?t

- Safety.

- Clinical effectiveness.

- Positive experience (defined as experiencing care which is responsive, patient-centred and delivered in a caring manner).

In order to meet these goals, providers should ensure that they:

- Are well-led.

- Use resources sustainably.

- Are equitable for all.

How to measure?‡

- Only use quality measures which have been validated in a transparent manner.

- Only use quality measures to compare services where relevant confounding factors are understood and can be adjusted for where appropriate.

- Where possible, align quality measures with existing data and frameworks; where additional data collection is needed, the benefits should be proportionate with the resources needed for data collection.

- Ensure that the measures reflect the priorities and perspectives of children, young people and families.

- 'No-one is better qualified to comment upon the quality of care provided by a paediatric centre than the children and young people receiving that care'.

*Source: Dixon et al. ${ }^{14}$

†Source: National Quality Board ${ }^{29}$ building on previous quality frameworks including the US Institute of Medicine Crossing the Quality Chasm report in 2001, ${ }^{30}$ framework and Lord Ara Darzi's High Quality Care for All (2008). ${ }^{31}$ $\ddagger$ Royal College of Paediatrics and Child Health. ${ }^{20}$

well-being outcomes. Most importantly, young people have consistently highlighted the need for services and professionals to recognise and address their distinct needs, and take an integrated approach to meeting those needs.
Lastly, while the NQB care domains are relevant to all age groups, adult-focused indicators and research will often need to be adapted and validated in order to be useful for CYP services. For example, although mortality is an important outcome for CYP-particularly for specific conditions and infants-death rates are fortunately much lower than among older adults. This highlights both the importance of publishing age-specific mortality rates, and the need for wider outcome measures that reflect long-term prognosis and quality of life, including resilience and attainment of lifelong goals. Similarly, although patient experience and patient-centredness of care have historically received much less attention for CYP than adults, and may need to be measured differently, CYP have the right to have their voice heard, ${ }^{1024}$ they provide information which cannot be gleaned from other sources, ${ }^{25}$ and they consistently rate feeling listened to as their most important care priority from the age of 8 onwards. ${ }^{26}$

\section{KEY THEMES TO GUIDE FUTURE QUALITY MEASUREMENT WORK FOR CYP SERVICES}

1. Increase awareness of, and engagement with, quality measurement for CYP.

Better quality measurement is key to improving health outcomes for CYP in the UK and is everyone's business. In order to engage front-line staff, measures must be perceived as fair and relevant to improving outcomes for their patients and must not impose a disproportionate burden of data collection.

\section{Improve collaboration and partnership working.}

No single organisation or group has the remit or resources to address all aspects of quality measurement for CYP. Coordinated working will support a common understanding of quality, avoid unnecessary duplication, facilitate learning and comparison across systems, and streamline the process of undertaking research and implementing research findings into routine quality assurance and QI practice.

3 . Focus on what matters most to children, young people and families.

Despite a welcome consensus about the importance of addressing children, young people and families' (CYPF) priorities, many gaps remain in current quality improvement and assurance programmes and research in this area. Addressing these gaps must be a priority in order to understand how CYPF's perspectives on quality may differ from those of other stakeholders, and how these perspectives can be explored and used.

\section{Simplify where possible.}

Quality measures and quality frameworks should strike the correct balance between simplicity and rigour. Complex measures, which result in a significant additional burden of data collection on clinical staff, are unlikely to be widely adopted. However, it is recognised that different measures will be needed for different contexts and that single, simple measures may need to be complemented by wider balancing or contextual measures.

5. Combine existing and new data sources. Many aspects of quality could be measured by more rigorous or creative use of existing and routinely collected data sources. Using existing data from Hospital Episode Statistics and survey data from patients, families and NHS staff will minimise costs and the burden of additional data collection on clinical staff. However, some gaps can only be addressed through commissioning new data sources.

\section{Link measurement to action.}

A workforce skilled in data analysis and QI methodology is essential so that better QI measurements can translate to sustained improvement in service quality. Similarly, quality assurance measures are very unlikely to have any sustained impact unless they are integrated with the existing frameworks for monitoring and inspecting service quality, such as those developed and used by the Care Quality Commission.

\section{CONCLUSIONS AND NEXT STEPS}

We cannot hope to understand or improve the quality of care that CYP receive in the NHS if we cannot agree on what to measure, for what purpose and how to do that in a coordinated fashion. This article reports the early discussions of a collaboration between national bodies to articulate and plan a shared vision of quality measurement for health services for CYP.

For national bodies, the first key recommendation is that, in future, quality measurement within NHS services for CYP should receive the same rigour and attention as within adult services. One example of this would be that appropriate validation and case-mix adjustment processes, which are routinely used for adult data, should be adapted and used for measures relating to CYP. ${ }^{27} 28$ Similarly, all relevant bodies should commit to working 
Table 1 Current quality measures for children and young people, challenges and priorities identified by selected national bodies

\begin{tabular}{|c|c|c|}
\hline & Which quality measures are currently in use or under development? & What are the major gaps/challenges/priorities to address in the future? \\
\hline NHS England & $\begin{array}{l}\text { Indicators in NHS structure, for example, commissioning indicators—obesity and } \\
\text { mental health. } \\
\text { Clinical Service Quality Metrics (currently in development)—asthma and diabetes } \\
\text { indicators. }\end{array}$ & $\begin{array}{l}\text { Gaps: holistic metrics. } \\
\text { Challenges: information governance and data linkage. } \\
\text { Priorities: metrics which focus on what matters to children and young people and } \\
\text { their parents/families/carers. }\end{array}$ \\
\hline Public Health England & $\begin{array}{l}\text { Child Health Profiles—-headline indicators for population health distributed to local } \\
\text { authorities on an annual basis—comparability and benchmarking. } \\
\text { Early year profiles - trend data. } \\
\text { Health visiting indicators. } \\
\text { Healthy behaviours in young people summaries. } \\
\text { Public Health and NHS Outcomes Frameworks for children (comparability, trends } \\
\text { and correlations). } \\
\text { Hospital utilisation. } \\
\text { CYP mental health and well-being system profiling too: indicator list (prevalence } \\
\text { data, estimates). } \\
\text { Recent data sets: CYP data set (linking community and acute hospital data sets). }\end{array}$ & $\begin{array}{l}\text { Gaps: dearth of data for young people. } \\
\text { Challenges: } \\
\text { 1. Increase awareness of data among people who need it most. } \\
\text { 2. Restrictions on data that can be used and ability to link data sets. } \\
\text { 3. Some of them are descriptive - may not be valid for understanding trends or } \\
\text { making comparisons. } \\
\text { 4. Limited to local populations, which limits comparisons. } \\
\text { Priorities: more data about/for young people. }\end{array}$ \\
\hline Care Quality Commission & $\begin{array}{l}\text { Bed occupancy for paediatric intensive care beds. } \\
\text { CQC children's survey. } \\
\text { Community Data Set.* } \\
\text { Emergency readmission rates. } \\
\text { Inflammatory bowel disease.* } \\
\text { Immunisation. } \\
\text { Late neonatal mortality. }{ }^{*} \\
\text { Maternity and Children's Data Set.* } \\
\text { Management of sepsis.* } \\
\text { Mental Health Services Data Set.* } \\
\text { Multiple emergency admissions for long-term conditions (asthma, epilepsy and } \\
\text { diabetes). } \\
\text { National congenital heart disease audit.* } \\
\text { National neonatal audit programme. } \\
\text { National paediatric diabetes audit. } \\
\text { Never events. } \\
\text { Non-elective neonatal readmissions. }{ }^{*} \\
\text { National Reporting and Learning System notifications. } \\
\text { Paediatric epilepsy audit.* } \\
\text { Paediatric intensive care audit. } \\
\text { Paediatric surgery indicators.* } \\
\text { Perinatal mortality. }{ }^{*} \\
\text { Safety thermometer. } \\
\text { Serious incidents. } \\
\text { Whistleblowing. }\end{array}$ & $\begin{array}{l}\text { Gaps/problems: we expect clinical services to be engaged in well-planned clinical } \\
\text { audit and we expect them to monitor their outcomes, to compare them with expected } \\
\text { results and to use them to drive improvements. } \\
\text { Challenges: there are not enough paediatric audits as yet to compare outcomes with } \\
\text { expected results for a wide range of common conditions. } \\
\text { Priorities: building partnerships with bodies that can develop better outcome } \\
\text { benchmarking tools. }\end{array}$ \\
\hline NICE & $\begin{array}{l}\text { Quality Outcomes Framework for general practice: asthma, diabetes, smoking } \\
\text { cessation support. } \\
\text { CCGs: diabetes care process and pregnancy and neonates. } \\
\text { In development: CYP with mental illness. }\end{array}$ & $\begin{array}{l}\text { Gaps: there are few indicators for paediatrics due to focus of work to date. } \\
\text { Challenges: data—risk of measuring what we always measure because we can } \\
\text { measure it. } \\
\text { Priorities: largely driven by Quality Standards work programme, but open to working } \\
\text { with key partners. }\end{array}$ \\
\hline $\begin{array}{l}\text { Healthcare Improvement Scotland } \\
\text { SPSP MCQIC }\end{array}$ & $\begin{array}{l}\text { National Quality Improvement programme } \\
\text { All Scottish NHS boards 'signed up'. } \\
\text { Full measurement plan for quality improvement data. } \\
\text { Monthly data submission. } \\
\text { Biannual data self-assessment by Scottish units with accompanying feedback from } \\
\text { national team at HIS. } \\
\text { Stakeholder engagement strategy with regular learning sessions/networking events/ } \\
\text { WebEx schedule. } \\
\text { Achievements of the paediatric care programme so far include the development of } \\
\text { a national system-wide Paediatric Early Warning Score and the development of the } \\
\text { Paediatric Sepsis Six. }\end{array}$ & $\begin{array}{l}\text { Gaps: } \\
\text { 1. Capacity and capability at board (local trust) level. } \\
\text { 2. Lack of national electronic data system. } \\
\text { 3. Benchmarking. } \\
\text { Challenges: lots of units focusing on process measures without monitoring } \\
\text { associated outcome measure. }\end{array}$ \\
\hline RCPCH \& Us Collaborative & \multicolumn{2}{|c|}{$\begin{array}{l}\text { Summary of recommendations for measuring and improving service quality } \\
\text { For all children and young people, especially regular patients with complex and lifelong conditions, it is vital a meaningful framework is able to follow their journey and progress } \\
\text { in a way that can be easily accessed by all agencies who support their needs. } \\
\text { It is right that each young person has a tailored plan to ensure their own requirements can be met, which is as accessible to them as it is to any clinician who has access to their } \\
\text { information. } \\
\text { Any feedback given has to be equally justified by the difference it will have on the service and to have a meaningful approach in improving quality of a young person's own } \\
\text { outcomes and for their peers. }\end{array}$} \\
\hline
\end{tabular}

*Indicators to be developed.

tMaternity core service measures.

For further details, please see the following links (all accessed on 14 February 2018):

NHS England: https://www.england.nhs.uk/publication/commissioning-for-quality-and-innovation-cquin-201617-indicators/; https://www.england.nhs.uk/ourwork/tsd/data-info/open-data/clinical-services-quality-measures/. Public Health England: https://fingertips.phe.org.uk/profile-group/child-health; https://fingertips.phe.org.uk/profile-group/child-health/profile/child-health-early-years; https://fingertips.phe.org.uk/profile-group/mental-health/profile/cypmh; http:// content.digital.nhs.uk/nhsof; http://content.digital.nhs.uk/maternityandchildren.

Care Quality Commission: http://www.cqc.org.uk/publications/surveys/children-young-peoples-survey-2016; https://www.cqc.org.uk/sites/default/files/20170629-IH-children-and-young-people-core-service-framework_0.pdf; https://www.rcpch. ac.uk/national-paediatric-diabetes-audit-npda; https://www.rcpch.ac.uk/epilepsy12; https://www.rcpch.ac.uk/improving-child-health/quality-improvement-and-clinical-audit/national-neonatal-audit-programme-nn-3; https://report.nrls.nhs.uk/ ac.uk/national-paediatric-diabetes-audit-npda; https://www.rcpch.ac.uk/cp

nrlsreporting/; https://www.safetythermometer.nhs.uk/index.php/c-yps.

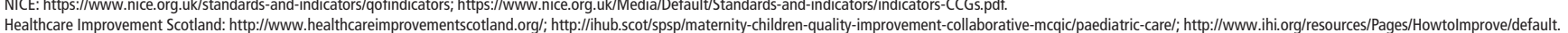
Healthcare Improvement Scotland: http://www.healthcareimprovementscotland.orgih

RCPCH \& Us: https://www.rcpch.ac.uk/improving-child-health/us-voice-children-young-people-and-families/us-voice-children-young-people-an.

CCG, Clinical Commissioning Group; CQC, Care Quality Commission; CYP, children and young people; HIS, Healthcare Improvement Scotland; NHS, National Health Service; MCQIC, Maternity \& Children Quality Improvement Collaborative; NICE, National Institute for Health and Care Excellence; SPSP, Scottish Patient Safety Programme

together and adopting a unified, evidencebased approach to quality measurement for CYP.

Regarding data challenges, we anticipate that some metrics will be derived from existing data, including clinical audits, primary and secondary care records, and patient experience surveys. These metrics are likely to align with strategic priorities identified above, such as improving patient experience, delivering more joined up care, improving transition from children to adult services, preventing avoidable admissions to hospital and keeping CYP safe while in hospital. Other metrics are likely to link to place-based quality metrics, including the early development index. However, there is a recognition 
that as this endeavour progresses, we will have to look beyond existing data sets and traditional healthcare-centric perspectives. In many cases, there is a clear need for new data sets to be commissioned which measure what matters most to CYP and their families-from outcomes and experience of CYP in primary care to new measures of educational, social and vocational outcomes for CYP with long-term conditions.

Acknowledgements We thank all the participants who contributed to the workshop on 10 May 2017. In particular, we thank the following RCPCH colleagues for their support in hosting, taking part in the workshop and helping with the writing up of the outputs: Professor Anne Greenough, Professor Judith Ellis, Professor Russell Viner, Emily Arkell, Rachel Winch and Lisa Cummins. We also thank The Health Foundation for supporting the workshop.

Contributors DSH, CL, CIE, JC, KT, ES and CRLHC conceived this article. DSH led the writing of the manuscript. All authors revised the manuscript and approved the final version.

Funding The authors have not declared a specific grant for this research from any funding agency in the public, commercial or not-for-profit sectors.

Competing interests None declared.

Patient consent Not required.

Provenance and peer review Not commissioned; externally peer reviewed.

\section{(6) \\ OPEN ACCESS}

Open access This is an open access article distributed in accordance with the Creative Commons Attribution Non Commercial (CC BY-NC 4.0) license, which permits others to distribute, remix, adapt, build upon this work non-commercially, and license their derivative works on different terms, provided the original work is properly cited and the use is non-commercial. See: http:// creativecommons.org/licenses/by-nc/4.0/

(c) Article author(s) (or their employer(s) unless otherwise stated in the text of the article) 2019. All rights reserved. No commercial use is permitted unless otherwise expressly granted.

Check for updates
To cite Hargreaves DS, Lemer $C$, Ewing $C$, et al. Arch Dis Child 2019;104:618-621.

Received 28 November 2017

Revised 15 March 2018

Accepted 16 March 2018

Published Online First 2 May 2018

\section{(5) Linked}

http://dx.doi.org/10.1136/

archdischild-2017-314638

Arch Dis Child 2019;104:618-621.

doi:10.1136/archdischild-2017-314564

\section{REFERENCES}

1 Davies SC. Our children deserve better: prevention pays. Annual report of the Chief Medical Officer 2012. London, 2013

2 Wolfe I, Macfarlane A, Donkin A, et al. Why children die: death in infants, children and young people in the UK. London: Royal College of Paediatrics and Child Health, 2014.

3 Wolfe I, Donkin A, Marmot M, et al. UK child survival in a European context: recommendations for a national Countdown Collaboration. Arch Dis Child 2015:100:907-14.

4 Viner RM, Hargreaves DS, Coffey C, et al. Deaths in young people aged $0-24$ years in the UK compared with the EU15+ countries, 1970-2008: analysis of the WHO Mortality Database. Lancet 2014;384:880-92.

5 Viner R, Hargreaves D, Cheung C. State of Child Health Report 2017. London: RCPCH, 2017.

6 UNICEF_Office_of_Research. Child Well-being in rich Countries: a comparative overview', innocenti report card 11. Florence: UNICEF, 2013.

7 Hargreaves DS, Viner RM. Children's and young people's experience of the National Health Service in England: a review of national surveys 2001-2011. Arch Dis Child 2012;97:661-6.

8 NPDA. National Paediatric Diabetes Audit Report 2015-16. London: RCPCH, 2016

9 Garrofe B, Bjornberg A, Phang A. Euro Diabetes Index. Health Consumer Power House Ltd, 2014.

10 United Nations. The United Nations Convention on the Rights of the Child. UK: UNICEF, 1989.

11 RCPCH. \&Us Participation. 2016. https://www.rcpch. ac.uk/andus-participation

12 Weil LG, Lemer C, Webb E, et al. The voices of children and young people in health: where are we now? Arch Dis Child 2015;100:915-7.

13 Nuffield Trust Quality Watch Team. Is the quality of care in England getting better? Quality watch annual statement. London: The Health Foundation; Nuffield Trust, 2013.

14 Dixon JS, Howells $E_{i}$, Mandel $A_{i}$, et al. Indicators of quality of care in general practices in England: an independent review for the Secretary of State for Health. 2015
15 Lewis IL, Lenehan C. Report of the children and young people's health outcomes forum 2012. 2012

16 NHS England. The NHS Outcomes Framework 2015/16. 2015.

17 Care Quality Commission. Children and young people's inpatient and day case survey 2014. 2015.

18 Royal College of Paediatrics and Child Health. Facing the future: standards for acute general paediatric services. 2015.

19 Royal College of Paediatrics and Child Health. Facing the future: together for child health. London: RCPCH, 2015.

20 Royal College of Paediatrics and Child Health. Service level quality improvement measures for acute general paediatrics service (SLQMAPS). London: RCPCH, 2016.

21 Woolfenden S; Freed G. A review of paediatric quality measures: development, testing and endorsement in the United States of America, Australia, United Kingdom and European Union. Melbourne, Australia: Murdoch Children's Research Institute, 2017

22 Downing A, Morris EJ, Corrigan N, et al. High hospital research participation and improved colorectal cancer survival outcomes: a population-based study. Gut 2017:66:89-96.

23 Care Quality Commission. Driving Improvement: case studies from 8 NHS Trust. 2017.

24 United_Nations. Sustainable Development Goals (SDGs). 2015. http://www.un.org/sustainabledevel opment/sustainable-development-goals/ (accessed 16 Feb 2018).

25 Hargreaves DS, Sizmur S, Pitchforth J, et al. Children and young people's versus parents' responses in an English national inpatient survey. Arch Dis Child 2018;103:486-91.

26 Bensted R, Hargreaves DS, Lombard J, et al. Comparison of healthcare priorities in childhood and early/late adolescence: analysis of cross-sectional data from eight countries in the Council of Europe Childfriendly Healthcare Survey, 2011. Child Care Health Dev 2015;41:160-5.

27 Wijlaars LP, Hardelid P, Woodman J, et al. Who comes back with what: a retrospective database study on reasons for emergency readmission to hospital in children and young people in England. Arch Dis Child 2016;101:714-8.

28 Blair M, Poots AJ, Lim V, et al. Preschool children who are frequent attenders in emergency departments: an observational study of associated demographics and clinical characteristics. Arch Dis Child 2018;103:19-23.

29 NHS England. National Quality Board. 2014. https:// www.england.nhs.uk/ourwork/part-rel/nqb/

30 Institute of Medicine. Crossing the quality chasm: a new health system for the 21st century. Washington: Institute of Medicine, 2001

31 Darzi A. High quality care for all. NHS next stage review final report. UK: Department of Health, 2008

32 Modi N. The case for child health. Arch Dis Child 2018:103:316-8. 